\title{
Clinical Neurological Profile of Patients with Leprosy in Fortaleza, Ceará, Brazil
}

Moacir Pereira Leite Neto', Francisco Marcos Bezerra da Cunha², Claudio Gleidiston Lima and Silva ${ }^{3}$, Luiz Carlos de Abreu ${ }^{4,5}$, Italla Maria Pinheiro Bezerra ${ }^{4}$, David Feder6, Fernando Luiz Affonso Fonseca ${ }^{4}$

\section{Abstract}

Introduction: Leprosy, still considered a public health problem in many countries, among them Brazil, causes multiple sensory and/or motor signs and symptoms of the peripheral nervous system (SMSSPNS). This study aimed to analyze a pretreatment neurological profile of patients with leprosy.

Methods: Cross-sectional study, whose participants 400 patients diagnosed with leprosy. Data collection took place through the collection from medical records and clinical examination of patients. It determined the frequency distribution of SMSSPNS, thickening of the nerves and committed peripheral nerves (PNC) as well as the sex and the average age.

Results: Over $93 \%$ of the patients presented at least 1 (one) sensory symptom, and hypoesthesia was the most prevalent among them. $59 \%$ displayed motor dysfunction and a $50.25 \%$ rate of neural thickening. Hypoesthesia had a higher prevalence among individuals whose symptoms appeared more than 12 (twelve) months ago (58.86\%, $p$ $=0.018$ ), and there was no association between other SMSSPNS and the disease's time of onset; or between SMSSPNS and CPN, according to the leprosy forms. The most affected nerve is the sensory-motor ulnar (57.48\%).

Conclusion: The most frequent alterations were categorized as sensitives, including hypoesthesia (with a higher prevalence in comparison to when it first appeared, more than 12 months ago) and impairment of the sensory-motor ulnar nerve.
1 Master's degree student. ABC Medical School. Professor of neurology at the Federal University of Cariri, Ce-Brazil.

2 Professor of neurology at the Federal University of Cariri, Ce-Brazil.

3 Professor of pathology at the Federal University of Cariri, Ce-Brazil.

4 Laboratory of Design and Scientific Writing. ABC Medical School, Santo André, SP, Brazil.

5 Harvard T.H. CHAN School of Public Health. Department of Environmental Health, 665 Huntington Avenue, Boston, MA 02115.

6 Full professor. ABC Medical School. Santo André, SP, Brazil.

\section{Contact information:}

\section{Fernando Luiz Affonso Fonseca.}

Address: Av. Príncipe de Gales, 821, Santo André, SP CEP 09060-650.

"'moacirleite@yahoo.com

Keywords

Leprosy; Neurologic

Manifestations; Peripheral

Nervous System Diseases. 


\section{Introduction}

Leprosy is an infectious clinical entity caused by a bacterium, the Mycobacterium leprae bacillus (M.L.) which causes, predominantly, dermatological and neurological compromise [1, 2, 3, 4]. This disease remains a public health issue in many countries, especially in Brazil, which is only surpassed by India in prevalence $[5,6,7,8]$.

Several classifications were produced to characterize the clinical forms of leprosy. The Ridley-Jopling classification is a comprehensive figure, enlisting the following types: tuberculoid-tuberculoid (TT), which is the most localized form, occurring in people that present an effective cellular immune response to the bacillus and a negative slit skin smear; lepromatous-lepromatous (LL), in which the cellular immune response to the $\mathrm{ML}$ is deficient or absent and smear-positive; and the intermediate forms of borderline-tuberculoid (BT), borderlineborderline $(\mathrm{BB})$ and borderline-lepromatous $(\mathrm{BL})$ $[9,10,11]$.

It has been shown that the neural compromise in leprosy is complex, due to multiple direct and indirect effects of the M.L. A direct effect consists in the demyelination of the peripheral nerve [12]. There are different forms of neural injuries experimentally observed, such as the segmental or paranodal demyelination and the axonal injury [13]. In advanced lesions, the segmental demyelination predominates in the $\mathrm{LL}$ and the Wallerian degeneration predominates in the TT form [13, 14].

The involvement of the peripheral nervous system in leprosy is variable and may range from damages to small cutaneous branches to the full compromise of nerve trunks $[15,16,17]$. In regard to the clinical aspects, this neurological involvement is present as mononeuropathy, multiple mononeuropathy or polyneuropathy [18, 19].

Peripheral nerve injury represents the leading cause of morbidity and may cause hypoesthesia or anesthesia, paresthesia, muscle atrophy, paresis, and functional limitations, resulting from it, directly or indirectly $[16,20,21,22,23]$. Neural thickness can be identified in varying degrees in literature [24, $25,26]$. Sensory impairment symptoms are most commonly reported, followed by symptoms of motor deficit. [27]

Leprosy can lead to several consequences, thereby the importance of early diagnosis and treatment [3, 4]. There is a lack of adequate training of non-specialized health professionals for a proper assessment of the function of the peripheral nerves, including many Reference Centers for Leprosy, which may be causing mistaken diagnosis [28].

Research should be implemented to give visibility to situations like these, however, while in Brazil the scientific production has been increasing significantly increase with the proper training of health professionals who work with research in project management [29]. Thus, studies identifying the main neurological changes in leprosy could result in more appropriate training strategies to better address the cases of neuropathy caused by leprosy.

Thus, the objective is to analyze the clinical and neurological profile of individuals with leprosy.

\section{Methods}

Cross-sectional descriptive study, with a sample of 400 patients. These are patients seen in outpatient neurology referral center for dermatology health of the Unified Health System in the city of Fortaleza, Ceará, Brazil, during the period March 2009 to March 2011.

The convenience sample consisted of patients diagnosed with leprosy and who had a confirmed diagnosis through laboratory routine and still had not received treatment by the time of the first specialized neurological evaluation; and the presence of signs and/or symptoms suggestive of peripheral neuropathy.

The leprosy diagnosis was established in the presence of one or more of the following cardinal signs: a) injury and/or skin area with sensitivity change; b) 
peripheral nerve impairment, with or without thickening, associated with sensory and/or motor and/ or autonomic changes; c) positive slit-skin smear.

The following exclusion criteria were considered: presence of medical condition, medication or exposure to substances that could cause peripheral neuropathy; presence of cognitive disorders and/or mental illnesses that prevented the understanding and the execution of the research; and refusal to join the research.

For the clinical evaluation phase were used data from patients contained in the medical records we utilized patient data inserted in medical records, which have a patterned structure that includes medical history, dermatological examination, neurological examination, simple laboratory routine, bacilloscopy research and other tests, which referred to the period of time prior to the leprosy treatment.

Based on the medical history of the patients, the research focused on skin lesions; and on motor and sensory changes (hypoesthesia, paresthesia and burning sensation). Considering that the medical records did not present a standard evaluation for autonomic abnormalities in physical or complementary tests, they were not included in the research.

The neurological workup included: 1 - palpation of peripheral nerves; 2 - evaluation of thermal, pain and tactile sensitivities; 3 - assessment of muscle strength, including muscles innervated by the ulnar nerve (5th digit abductor, 1st dorsal interosseous, interosseous, and 3rd and 4th digits lumbricoids), innervated by the median nerve (short abductor of the thumb), innervated by the radial nerve (common extensor digits and radial carpal extensor), innervated by the common peroneal/fibular nerve (tibialis anterior, extensor hallucis longus, extensor common digits, peroneus longus and short and third fibular), innervated by the posterior tibial nerve (short flexor hallucis and abductor hallucis) and innervated by the facial nerve (frontal, orbicularis eye, buccinator, orbicularis of the biggest lips and zygomatic); 4 - evaluation of biceps, triceps, brachioradialis, patellar, achilles, masseterino and orbicularis oculi bone-tendon reflexes; and of corneal-palpebral and skin-plant reflexes; 5 - muscle tropism.

The simple laboratory routine performed in all patients included serum tests evaluating: CBC, erythrocyte sedimentation rate, urea, creatinine, electrolytes (sodium, potassium, calcium, magnesium), fasting glucose, aspartate aminotransferase, alanine aminotransferase, fosfocreatinoquinase, thyroid function (TSH, free T3 and free T4), partial urinalysis, stool analysis and bacilloscopy research in the lymph. Additional tests were performed on specific cases of other suspected diseases. Electromyographies were performed in part of the patients by the same clinical neurophysiologist.

Thereby, based on the findings obtained through the clinical evaluation, a division was carried out, considering the gender and the average age of the research subjects. The research proceeded to investigate the occurrence of neurological alterations on the group of patients of the whole sample and on each of the forms of leprosy listed in the Ridley-Jopling classification. The occurrence of each neurological disorder, in the complete sample, was analyzed according to the appearance period of the symptoms.

The researched neurological abnormalities included sensory changes (hypoesthesia, tingling and burning) and motor disorders (paresis and atrophy). Likewise, the isolated occurrence of each of the aforementioned sensory and motor symptoms and of neural thickening was investigated.

Furthermore, the study detected the occurrence of impairment of some peripheral nerves (sensorymotor ulnar, sensory-motor median, radial motor, sensory ulnar, sensory median, superficial branch of the radial, superficial dorsal branch of the ulnar, lateral cutaneous of the forearm, anterior cutaneous of the forearm, deep fibular/peroneal, posterior tibial, surface peroneal, medial and lateral plantar, su- 
ral, saphenous, lateral cutaneous of the tight/lateral femoral cutaneous, retroauricular and other nerves) in the group of patients from the entire sample and in each of the leprosy forms listed in the RidleyJopling classification.

In this case, only 243 patients underwent biopsy and classified and there was no identification of the peripheral nerve affected in the medical records of 23 patients who did not undergo biopsy and 36 patients who underwent biopsy. This fact reduced the sample of patients for peripheral nerve analysis affected.

Data were organized into an electronic database, using Microsoft's Excel software. The software $R$ (The R Project for Statistical Computing) was used to perform the statistical analysis [30].

The descriptive analysis was implemented through frequency distribution, which was measured: by the number of cases and percentages, for categorical variables; and by the arithmetic mean, for the quantitative variable of age. Then, in order to execute an evaluation by inferential statistics, the chi-square test was utilized to verify the association between variables, adopting a significance value of $5 \%$. It represents the most appropriate parametric test to verify the association between 2 (two) categorical variables (qualitative).

The research was approved on September 13, 2007; by the Document CEP/CEDERM-011/07, issued by the Research Ethics Committee of the Sanitary Dermatology Referral Center Dona Libânia, and met the recommendations of the Declaration of Helsinki. It also obtained the authorization of the employee responsible for the mentioned institution; and all patients included in the study signed a free and informed consent form. The research was not subsidized by companies or research support institutions, having been funded exclusively by the researchers. The researchers state that there was no conflict of interest.

\section{Results}

Thereby, of the 400 patients included in the study, 219 were male and 181 were female. The average age was 41.7 years; nevertheless, the average age for males was 41.6 years and for females was 41.9 years.

The other results are shown in the related tables (1-5).

Table 1. Distribution of neurological disorders in patients diagnosed with leprosy. Fortaleza, Brazil, 2009-2011.

\begin{tabular}{|c|c|c|c|c|c|c|}
\hline \multirow{3}{*}{ Factors } & \multicolumn{6}{|c|}{ Impairment } \\
\hline & \multicolumn{2}{|c|}{ Yes } & \multicolumn{2}{|c|}{ No } & \multicolumn{2}{|c|}{ Total } \\
\hline & $n$ & $\%$ & $\mathrm{n}$ & $\%$ & $n$ & $\%$ \\
\hline Pricking & 244 & 61 & 156 & 39 & 400 & 100 \\
\hline Burning & 224 & 56 & 176 & 44 & 400 & 100 \\
\hline Hypoesthesia & 367 & 91.75 & 33 & 8.25 & 400 & 100 \\
\hline Paresis & 164 & 41 & 236 & 59 & 400 & 100 \\
\hline $\begin{array}{l}\text { Muscle } \\
\text { atrophy }\end{array}$ & 138 & 34.5 & 262 & 65.6 & 400 & 100 \\
\hline $\begin{array}{l}\text { Neural } \\
\text { thickening }\end{array}$ & 201 & 50.25 & 199 & 49.75 & 400 & 100 \\
\hline $\begin{array}{l}\text { Any sensitivity } \\
\text { change }\end{array}$ & 372 & 93 & 28 & 7 & 400 & 100 \\
\hline $\begin{array}{l}\text { Any motor } \\
\text { change }\end{array}$ & 236 & 59 & 164 & 41 & 400 & 100 \\
\hline
\end{tabular}

Table 2. Distribution of neurological disorders in patients diagnosed with leprosy. Fortaleza, Brazil, 2009-2011.

\begin{tabular}{|c|c|c|c|c|c|c|c|}
\hline \multirow{3}{*}{ Factors } & \multicolumn{6}{|c|}{ Impairment } & \multirow{3}{*}{$p$} \\
\hline & \multicolumn{2}{|c|}{ Yes } & \multicolumn{2}{|c|}{ No } & \multicolumn{2}{|c|}{ Total } & \\
\hline & $n$ & $\%$ & $n$ & $\%$ & $n$ & $\%$ & \\
\hline $\begin{array}{l}\text { Neural } \\
\text { thickening }\end{array}$ & 39 & 51.32 & 53 & 54.64 & 109 & 48.08 & 0.539 \\
\hline Hypoesthesia & 66 & 17.98 & 85 & 23.16 & 216 & 58.86 & 0.018 \\
\hline Pricking & 48 & 63.16 & 58 & 59.79 & 138 & 60.79 & 0.899 \\
\hline Burning & 44 & 57.89 & 54 & 55.67 & 126 & 55.51 & 0.934 \\
\hline Paresis & 26 & 34.31 & 36 & 37.11 & 102 & 44.93 & 0.173 \\
\hline $\begin{array}{l}\text { Muscle } \\
\text { atrophy }\end{array}$ & 22 & 28.95 & 29 & 29.90 & 87 & 38.33 & 38.33 \\
\hline
\end{tabular}


Vol. 8 No. 218 doi: $10.3823 / 1817$

Observing Table 1, hypoesthesia was identified in $91.75 \%$ of patients ( $n=367)$, tingling sensation in $61 \%$ of cases $(n=244)$, burning in $56 \%$ of cases, $41 \%$ paresis, muscular atrophy in 34.5\% , sensitive alteration in $93 \%$ and motor changes by $59 \%$.

Table 2 shows that numbness occurred among individuals who have onset of symptoms more than twelve (12) months prior to clinical evaluation in $58.86 \%$ of cases $(n=216)$, with $p=0.018$, tingling was identified affecting $63,16 \%(n=48)$ in case of preceding the onset of symptoms by up to six (6) months of evaluation, $p=0.899$, and burning in $57.89 \%$ of cases $(n=44)$ subjects in this same time period, with $p=0.934$. In cases of symptoms started over twelve (12) months before, motor deficit were present in $44.93 \%$ of the patients ( $n=$ 102 ), $p=0.173$, and muscle atrophy in $38.33 \%$ ( $n$ $=87)$; with $p=0.181$.

In Table 3, the data illustrate that the ulnar motor and sensory nerve affected $57.48 \%$ of subjects ( $n=$ 196), the surface peroneal was affected in $44.57 \%$ of patients ( $n=152$ ) and the posterior tibial was affected in $30.79 \%$ of subjects $(n=105)$.

In Table 4 we see hypoesthesia in this case 93.75\% BL ( $n=15)$, tingling $81.25 \%$ of cases $B L(n$ $=13)$, burn in $81.25 \%$ of cases $B L(n=28)$, paresis
Table 3. Occurrence of nerve involvement according to the elapsed time from the onset of symptoms in patients diagnosed with leprosy. Fortaleza, Brasi, 2009-2011.

\begin{tabular}{|l|c|c|}
\hline \multirow{2}{*}{\multicolumn{1}{|c|}{ Impaired nerves }} & \multicolumn{2}{|c}{ Values } \\
\cline { 2 - 3 } & $n$ & $\%$ \\
\hline Sensory-motor ulnar & 196 & 57.48 \\
\hline Surface peroneal & 152 & 44.57 \\
\hline Posterior tibial & 105 & 30.79 \\
\hline Sural & 99 & 29.03 \\
\hline Medial and lateral plantar & 97 & 28.45 \\
\hline Deep peroneal & 96 & 28.15 \\
\hline Superficial branch of the radial & 79 & 23.17 \\
\hline Sensory-motor median & 68 & 19.94 \\
\hline Sensory ulnar & 59 & 17.3 \\
\hline Sensory median & 58 & 17.01 \\
\hline Superficial dorsal branch of the ulnar & 49 & 14.37 \\
\hline Radial motor & 41 & 12.02 \\
\hline Saphenous & 40 & 11.73 \\
\hline Retroauricular & 23 & 6.74 \\
\hline Lateral femoral cutaneous & 15 & 4.4 \\
\hline Lateral cutaneous of the forearm & 2 & 1.17 \\
\hline Anterior cutaneous of the forearm & 0.59 \\
\hline Other nerves & 6.74 \\
\hline
\end{tabular}

Table 4. Distribution of neurological disorders in the strata of the sample according to the forms of leprosy in accordance with the elapsed time from the onset of symptoms in patients diagnosed with leprosy. Fortaleza, Brazil, 2009-2011.

\begin{tabular}{|c|c|c|c|c|c|c|c|c|c|c|c|c|}
\hline \multirow{3}{*}{ Neurological disorder } & \multicolumn{11}{|c|}{ Impairment } & \multirow{3}{*}{$P$} \\
\hline & \multicolumn{2}{|c|}{ TT } & \multicolumn{2}{|c|}{ BT } & \multicolumn{2}{|c|}{$\mathrm{BB}$} & \multicolumn{2}{|c|}{$\mathrm{BL}$} & \multicolumn{2}{|c|}{ LL } & \multirow{2}{*}{$\begin{array}{c}\text { Total } \\
\mathrm{n}\end{array}$} & \\
\hline & $\mathrm{n}$ & $\%$ & $n$ & $\%$ & $n$ & $\%$ & $\mathrm{n}$ & $\%$ & $n$ & $\%$ & & \\
\hline \multicolumn{13}{|l|}{ Hypoesthesia } \\
\hline Yes & 47 & 88.68 & 113 & 93.39 & 11 & 91.67 & 15 & 93.75 & 37 & 90.24 & 223 & \multirow{2}{*}{0.86} \\
\hline No & 6 & 11.32 & 8 & 6.61 & 1 & 8.33 & 1 & 6.25 & 4 & 9.76 & 20 & \\
\hline \multicolumn{13}{|l|}{ Pricking } \\
\hline Yes & 33 & 62.26 & 67 & 55.37 & 6 & 50 & 13 & 81.25 & 28 & 68.29 & 147 & \multirow{2}{*}{0.21} \\
\hline No & 20 & 37.74 & 54 & 44.63 & 6 & 50 & 3 & 18.75 & 13 & 31.71 & 96 & \\
\hline
\end{tabular}




\begin{tabular}{|c|c|c|c|c|c|c|c|c|c|c|c|c|}
\hline \multirow{3}{*}{ Neurological disorder } & \multicolumn{12}{|c|}{ Impairment } \\
\hline & \multicolumn{2}{|c|}{ TT } & \multicolumn{2}{|c|}{ BT } & \multicolumn{2}{|c|}{ BB } & \multicolumn{2}{|c|}{$\mathrm{BL}$} & \multicolumn{2}{|c|}{ LL } & \multirow{2}{*}{$\begin{array}{c}\text { Total } \\
n\end{array}$} & \multirow{2}{*}{$P$} \\
\hline & $n$ & $\%$ & $\mathrm{n}$ & $\%$ & $\mathrm{n}$ & $\%$ & $\mathrm{n}$ & $\%$ & $\mathrm{n}$ & $\%$ & & \\
\hline \multicolumn{13}{|l|}{ Burning } \\
\hline Yes & 32 & 60.38 & 60 & 49.59 & 5 & 41.67 & 13 & 81.25 & 27 & 65.85 & 137 & \multirow{2}{*}{0.06} \\
\hline No & 21 & 39.62 & 61 & 50.41 & 7 & 58.33 & 3 & 18.75 & 14 & 34.15 & 106 & \\
\hline \multicolumn{13}{|l|}{ Paresis } \\
\hline Yes & 33 & 62.26 & 41 & 33.88 & 5 & 41.6 & 8 & 50 & 18 & 43.9 & 99 & \multirow{2}{*}{0.86} \\
\hline No & 20 & 37.74 & 80 & 65.12 & 7 & 58.33 & 8 & 50 & 23 & 56.10 & 144 & \\
\hline \multicolumn{13}{|l|}{ Muscle atrophy } \\
\hline Yes & 20 & 37.74 & 34 & 28.10 & 5 & 41.6 & 6 & 37.5 & 14 & 34.15 & 79 & \multirow{2}{*}{0.66} \\
\hline No & 33 & 62.26 & 87 & 71.90 & 7 & 58.33 & 10 & 62.5 & 27 & 65.85 & 164 & \\
\hline \multicolumn{13}{|l|}{ Neural thickening } \\
\hline Yes & 27 & 50.94 & 59 & 48.76 & 3 & 25 & 6 & 37.5 & 19 & 46.34 & 114 & \multirow{2}{*}{0.49} \\
\hline No & 26 & 49.06 & 62 & 51.24 & 0 & 75 & 10 & 62.5 & 22 & 53.66 & 129 & \\
\hline \multicolumn{13}{|l|}{ Any sensitivity change } \\
\hline Yes & 49 & 92.45 & 119 & 98.35 & 12 & 100 & 16 & 100 & 38 & 92.68 & 234 & \multirow{2}{*}{0.18} \\
\hline No & 4 & 7.55 & 2 & 1.65 & 0 & 0.0 & 0 & 0.0 & 3 & 7.37 & 9 & \\
\hline \multicolumn{13}{|l|}{ Any motor change } \\
\hline Yes & 37 & 69.81 & 72 & 59.5 & 9 & 75 & 12 & 75 & 31 & 75.61 & 161 & \multirow{2}{*}{0.26} \\
\hline No & 16 & 30.19 & 48 & 40.5 & 3 & 25 & 4 & 25 & 10 & 24.39 & 82 & \\
\hline Total & 53 & 100 & 121 & 100 & 12 & 100 & 16 & 100 & 41 & 100 & 243 & \\
\hline
\end{tabular}

in $33.8 \%$ of cases BT $(n=41)$, and muscular atrophy in $28.1 \%$ of cases BT $(n=34)$.

Table 5 reports that the commitment of the sensory-motor ulnar nerve was found in $60.9 \%$ of cases of BT $(n=64)$, with $p=0.55$. The commitment of the superficial peroneal nerve was found in $51.4 \%$ of cases of BT $(n=54)$, with $p=$ 0.17 , and involvement of the posterior tibial nerve was found in $33.3 \%$ of cases of BT $(n=33)$, with $p=0.13$.

Table5. Occurrence of nerve involvement in the strata of the sample according to the forms of leprosy. Fortaleza, Brazil, 2009-2011

\begin{tabular}{|c|c|c|c|c|c|c|c|c|c|c|c|c|}
\hline \multirow{3}{*}{ Nerve } & \multicolumn{11}{|c|}{ Impairment } & \multirow{3}{*}{$P$} \\
\hline & \multicolumn{2}{|c|}{ TT } & \multicolumn{2}{|c|}{ BT } & \multicolumn{2}{|c|}{ BB } & \multicolumn{2}{|c|}{$B L$} & \multicolumn{2}{|c|}{ LL } & \multirow{2}{*}{$\begin{array}{c}\text { Total } \\
n\end{array}$} & \\
\hline & $n$ & $\%$ & $n$ & $\%$ & $n$ & $\%$ & $n$ & $\%$ & $n$ & $\%$ & & \\
\hline \multicolumn{13}{|c|}{ Sensory-motor ulnar } \\
\hline Yes & 28 & 59.57 & 64 & 60.95 & 3 & 37.5 & 6 & 46.15 & 22 & 64.71 & 123 & \multirow{2}{*}{0.55} \\
\hline No & 19 & 40.43 & 41 & 39.05 & 5 & 62.5 & 7 & 53.85 & 12 & 35.29 & 84 & \\
\hline
\end{tabular}




\begin{tabular}{|c|c|c|c|c|c|c|c|c|c|c|c|c|}
\hline \multirow{3}{*}{ Nerve } & \multicolumn{11}{|c|}{ Impairment } & \multirow{3}{*}{$P$} \\
\hline & \multicolumn{2}{|c|}{ TT } & \multicolumn{2}{|c|}{ BT } & \multicolumn{2}{|c|}{ BB } & \multicolumn{2}{|c|}{$B L$} & \multicolumn{2}{|c|}{ LL } & \multirow{2}{*}{$\begin{array}{c}\text { Total } \\
\mathrm{n}\end{array}$} & \\
\hline & $n$ & $\%$ & $\mathrm{n}$ & $\%$ & $n$ & $\%$ & $n$ & $\%$ & $n$ & $\%$ & & \\
\hline \multicolumn{13}{|c|}{ Sensory-motor median } \\
\hline Yes & 6 & 12.77 & 24 & 22.86 & 0 & 0 & 5 & 38.46 & 5 & 14.71 & 40 & \multirow{2}{*}{0.11} \\
\hline No & 41 & 87.23 & 81 & 77.14 & 8 & 100 & 8 & 61.54 & 29 & 85.29 & 167 & \\
\hline \multicolumn{13}{|l|}{ Radial motor } \\
\hline Yes & 9 & 19.15 & 11 & 10.48 & 0 & 0 & 2 & 15.38 & 3 & 8.82 & 25 & \multirow{2}{*}{0.40} \\
\hline No & 387 & 80.85 & 94 & 89.52 & 8 & 100 & 11 & 84.62 & 31 & 91.18 & 182 & \\
\hline \multicolumn{13}{|l|}{ Sensory ulnar } \\
\hline Yes & 7 & 14.89 & 22 & 20.95 & 0 & 0 & 1 & 7.69 & 5 & 14.71 & 35 & \multirow{2}{*}{0.42} \\
\hline No & 40 & 85.11 & 83 & 79.05 & 8 & 100 & 12 & 92.31 & 29 & 85.29 & 172 & \\
\hline \multicolumn{13}{|l|}{ Sensory median } \\
\hline Yes & 5 & 10.64 & 20 & 19.05 & 1 & 12.5 & 1 & 7.69 & 4 & 11.76 & 31 & \multirow{2}{*}{0.57} \\
\hline No & 42 & 89.36 & 85 & 80.95 & 7 & 87.5 & 12 & 92.31 & 30 & 88.24 & 176 & \\
\hline \multicolumn{13}{|c|}{ Superficial branch of the radial } \\
\hline Yes & 10 & 21.28 & 26 & 24.76 & 1 & 12.5 & 2 & 15.38 & 7 & 20.59 & 46 & \multirow{2}{*}{0.87} \\
\hline No & 37 & 78.72 & 79 & 75.24 & 7 & 87.5 & 11 & 84.62 & 12 & 35.29 & 161 & \\
\hline \multicolumn{13}{|c|}{ Superficial dorsal branch of the ulnar } \\
\hline Yes & 5 & 10.64 & 16 & 15.24 & 0 & 0 & 1 & 7.69 & 4 & 11.76 & 26 & \multirow{2}{*}{0.68} \\
\hline No & 42 & 89.36 & 89 & 84.76 & 8 & 100 & 12 & 92.31 & 30 & 88.24 & 181 & \\
\hline \multicolumn{13}{|c|}{ Lateral cutaneous of the forearm } \\
\hline Yes & 0 & 0 & 2 & 1.9 & 0 & 0 & 0 & 0 & 1 & 2.94 & 3 & \multirow{2}{*}{0.79} \\
\hline No & 47 & 100 & 103 & 98.1 & 8 & 100 & 13 & 100 & 33 & 97.06 & 204 & \\
\hline \multicolumn{13}{|c|}{ Anterior cutaneous of the forearm } \\
\hline Yes & 0 & 0 & 2 & 1.9 & 0 & 0 & 0 & 0 & 0 & 0 & 2 & \multirow{2}{*}{0.74} \\
\hline No & 47 & 100 & 103 & 98.1 & 8 & 100 & 13 & 100 & 34 & 100 & 205 & \\
\hline Deep peroneal & & & & & & & & & & & & \\
\hline Yes & 13 & 27.66 & 36 & 34.39 & 3 & 37.5 & 3 & 23.08 & 7 & 20.59 & 62 & 56 \\
\hline No & 34 & 72.34 & 69 & 65.71 & 5 & 62.5 & 10 & 76.92 & 12 & 35.29 & 145 & 0.0 \\
\hline Posterior tibial & & & & & & & & & & & & \\
\hline Yes & 12 & 25.53 & 33 & 33.33 & 2 & 26 & 1 & 7.69 & 15 & 44.12 & 65 & 2 \\
\hline No & 35 & 74.47 & 70 & 66.67 & 6 & 65 & 12 & 92.31 & 19 & 55.88 & 142 & J \\
\hline Surface peroneal & & & & & & & & & & & & \\
\hline Yes & 18 & 38.30 & 54 & 51.43 & 4 & 50 & 10 & 23.08 & 12 & 35.29 & 91 & \\
\hline No & 29 & 61.70 & 51 & 48.57 & 4 & 50 & 13 & 76.92 & 22 & 64.71 & 116 & 0.11 \\
\hline
\end{tabular}




\begin{tabular}{|c|c|c|c|c|c|c|c|c|c|c|c|c|}
\hline \multirow{3}{*}{ Nerve } & \multicolumn{11}{|c|}{ Impairment } & \multirow{3}{*}{$P$} \\
\hline & \multicolumn{2}{|c|}{ TT } & \multicolumn{2}{|c|}{ BT } & \multicolumn{2}{|c|}{$\mathrm{BB}$} & \multicolumn{2}{|c|}{$\mathrm{BL}$} & \multicolumn{2}{|c|}{$\mathrm{LL}$} & \multirow{2}{*}{$\begin{array}{c}\text { Total } \\
n\end{array}$} & \\
\hline & $n$ & $\%$ & $n$ & $\%$ & $n$ & $\%$ & $\mathrm{n}$ & $\%$ & $\mathrm{n}$ & $\%$ & & \\
\hline \multicolumn{13}{|c|}{ Medial and lateral plantar } \\
\hline Yes & 12 & 25.53 & 27 & 25.71 & 4 & 50 & 3 & 23.08 & 10 & 29.41 & 56 & \multirow{2}{*}{0.65} \\
\hline No & 35 & 74.47 & 78 & 74.29 & 4 & 50 & 10 & 76.92 & 24 & 70.59 & 151 & \\
\hline \multicolumn{13}{|l|}{ Sural } \\
\hline Yes & 10 & 21.28 & 31 & 29.52 & 2 & 25 & 2 & 15.38 & 9 & 26.47 & 54 & \multirow{2}{*}{0.74} \\
\hline No & 37 & 78.72 & 74 & 70.48 & 6 & 65 & 11 & 84.62 & 25 & 73.53 & 153 & \\
\hline \multicolumn{13}{|l|}{ Saphenous } \\
\hline Yes & 5 & 10.64 & 13 & 12.38 & 0 & 0 & 0 & 0 & 2 & 5.88 & 20 & \multirow{2}{*}{0.44} \\
\hline No & 42 & 89.36 & 92 & 87.62 & 8 & 100 & 13 & 100 & 32 & 94.12 & 187 & \\
\hline \multicolumn{13}{|c|}{ Lateral femoral cutaneous } \\
\hline Yes & 1 & 2.13 & 3 & 2.86 & 0 & 0 & 1 & 7.69 & 3 & 8.82 & 8 & \multirow{2}{*}{0.44} \\
\hline No & 46 & 97.87 & 102 & 97.14 & 8 & 100 & 12 & 92.31 & 31 & 91.18 & 199 & \\
\hline \multicolumn{13}{|l|}{ Retroauricular } \\
\hline Yes & 5 & 10.64 & 4 & 3.81 & 1 & 12.5 & 1 & 7.69 & 2 & 5.88 & 13 & \multirow{2}{*}{0.53} \\
\hline No & 42 & 89.36 & 101 & 96.19 & 7 & 87.5 & 12 & 92.31 & 32 & 94.12 & 194 & \\
\hline \multicolumn{13}{|l|}{ Other nerves } \\
\hline Yes & 4 & 8.51 & 6 & 5.71 & 1 & 12.5 & 1 & 7.69 & 3 & 8.82 & 15 & \multirow{2}{*}{0.92} \\
\hline No & 43 & 91.49 & 99 & 94.29 & 7 & 87.55 & 12 & 92.31 & 31 & 91.18 & 192 & \\
\hline Total & 47 & 100 & 105 & 100 & 8 & 100 & 13 & 100 & 34 & 100 & 207 & \\
\hline
\end{tabular}

\section{Discussion}

In the sample, there was a slight predominance of males, with an average age of approximately 41 years.

A analysis of the neurological changes throughout the entire sample (Table 1) indicates that most individuals presented some kind of sensory neurological symptom, and it was detected that sensory symptoms were more frequent than motor dysfunction symptoms. Over $93 \%$ of the subjects presented, at least, one sensory neurological symptom, which could comprehend hypoesthesia, tingling and/or burning. Among these, hypoesthesia was the most prevalent symptom, followed by tingling and burning.
In regard to the motor dysfunction by the presence of paresis and/or muscle atrophy, most individuals equally presented some of these characteristics; however, most individuals did not separately present paresis or muscle atrophy. Neural thickening was present in slightly more than half of the individuals. In a cohort study developed in India, sensory impairment was more frequently found [31]. Nevertheless, in a series of cases investigated at the Osvaldo Cruz Institute (Brazil), paresthesia was identified as the most frequent symptom, followed by paresis and neural thickening [32].

Patients with leprosy may suffer a decrease in sensitivity, due to the bacterial invasion of a nerve trunk or terminal receiving unit; and, from a clinical standpoint, a manifestation occurs when $25 \%$ 
to $30 \%$ of nerve fibers in a nerve trunk become non-functional and all sensitivity modalities are lost, except for the joint position sense, whose nerve impulses travel through a tendon, not through nerve trunks [33]. Literature also lists the impairment of motor and autonomic fibers [34].

The present research did not aim to analyze the symptoms of autonomic dysfunction, but ascertained the presence of sensory and motor symptoms, and of neural thickening. Once the sample was convenience, it did not have the purpose of evaluating leprosy patients in general, but only the patients with leprosy and clinical aspects indicative of some peripheral nerve injury.

The onset time of symptoms was also evaluated according to the presence of neurological changes (Table 2). It was observed that the highest prevalence of hypoesthesia occurred among individuals whose symptoms appeared more than 12 (twelve) months ago and that more than half of the patients presented this symptom, with a significant association also occurring $(p=0.018)$.

Tingling was more prevalent in individuals whose symptoms started within 6 (six) months, affecting most individuals, as well as the burning; however, there was no association between the onset time of the disease and these two symptoms ( $p=0.899$ and $p=0.934$, respectively). Thus, by linking the motor dysfunction to the symptoms onset time, the study showed (see Table 03) that individuals who presented symptoms for more than 12 (twelve) months are those who had a higher prevalence for the occurrence of motor deficit and muscle atrophy, without association ( $p=0.173$ and $p=0.181$, respectively). It is known that the nerve damage is caused by mechanisms that rapidly evolve and that it is present even at the early stages of the disease, observed through changes in sensitivity; however, the lack of treatment results in its progressive worsening [13].

The INFIR cohort study identified $50 \%$ of ancient sensory impairment cases that lasted more than 6 months, and $12,2 \%$ of motor impairment cases trough the analysis of 74 total cases; however, it represented a cohort study including only patients with borderline and lepromatous forms [35]. A comment to be included on this research is that, in multibacillary forms, there was a slight predominance of sensory and motor changes. The BANDS study discovered a strong predominance of neural function loss in patients with multibacillary forms at the time of the first evaluation. [36]

Table 3 expresses that, in over half of the cases, the most affected nerve was the sensory-motor ulnar. The other 2 (two) most affected nerves, in order, were the surface peroneal and the posterior tibial. A different perspective was adopted in a cohort study conducted in India and published in 1998, where the posterior tibial nerve was appointed as the most frequent case of sensory and motor nerve impairment; followed by the lateral fibular/ peroneal nerve, among the cases of sensory impairment; and by the ulnar nerve, among the cases of motor impairment [33].

A methodological distinction must be emphasized: in the aforementioned study developed in India and published in 1988, the nerve stratification happened according to the sensory or motor alteration; meanwhile, in the present work, the stratification happened according to the nerve impairment and to the leprosy forms. It is worth mentioning that, in the indian research, it is not possible to determine the cases when motor and sensory impairments happened simultaneously. The BANDS study found that the posterior tibial was the most commonly affected nerve, followed by the ulnar nerve [37]. Likewise, in a series of cases developed in Cuba, the ulnar nerve was identified as the most commonly affected [38].

The assessment of signs and symptoms of neurological alterations in each of the forms of leprosy (Table 4) indicated that there was no association between these variables; however, while trying to develop a link between the burning symptom va- 
riable and the leprosy forms, a adjacent $p$ value of 0.06 was obtained, which indicates a possible association. In the sample of 243 patients who underwent biopsy and pathological examination, the most common neurological disorder was hypoesthesia, in all forms of leprosy. In cases of tuberculoid form, paresis was highlighted for being the second most common finding, occurring in an equal proportion to the tingling sensation.

Tingling was the second most common symptom in all other forms of the disease. Neural thickening was more present in the tuberculoid and borderline-tuberculoid forms, in which it was identified in about half of the patients. In patients presenting sensory and motor abnormalities, the most common form was the borderline-tuberculoid, followed by tuberculoid. Solomon also reported the borderline-tuberculoid form as the most commonly identified in patients with sensory or motor impairment/alteration, followed by the tuberculoid form [33].

The evaluation of impaired peripheral nerves, according to each of the forms of leprosy (Table 5), indicated no association of variables. In the sample of 243 patients evaluated in accordance with the Ridley and Jopling classification, the study demonstrated that, in cases of leprosy of tuberculoid, borderline-tuberculoid, borderline-lepromatous and lepromatous forms, the most often injured nerve was the sensory-motor ulnar.

In cases of patients with leprosy in the borderline-borderline form, the surface peroneal and the medial and lateral plantar nerves were most frequently compromised. The surface peroneal still was the second most affected nerve in the tuberculoid and borderline-tuberculoid forms. In the borderlinelepromatous form, the sensory-motor median nerve was the second most affected; and, in the lepromatous form, the posterior tibial was the second most inflicted nerve.

\section{Conclusion}

The study detected that sensory change findings are more frequent than those of motor dysfunction, and that hypoesthesia is the most prevalent symptom. Hypoesthesia occurred, most frequently, in cases of symptoms arising for more than 12 (twelve) months, with significant association; however, there was no association between the onset time of symptoms and the others researched neurological disorders.

The most affected nerve was the sensory-motor ulnar, followed by the surface peroneal. During the assessment of neurological changes in each of the leprosy forms, no association between these variables was discovered; even though, it should be noted that an adjacent $p$ value of 0.06 , regarding the association of the burning symptom to the forms of leprosy, was found, and that a decreased sensitivity was more frequently present in all forms of leprosy. Likewise, the study did not observe a association between the impaired peripheral nerves and the leprosy forms; identifying, in the sample, that the most often injured nerve in the tuberculoid, borderline-tuberculoid, borderline-lepromatous and lepromatous forms was the sensory-motor ulnar; and that, in the borderline-borderline form, were the surface peroneal nerve and the medial and lateral plantar nerves.

Future researches can develop a broader analysis of the aspects concerning their workup, including autonomic symptoms; and reassess the existence of an association between the burning symptom and the leprosy forms. Health services can benefit from these studies, based on clinical characteristics, during the preparation of training programs that better capacitate health professionals who deal with this disease on a daily basis. 


\section{References}

1. Levinson, Warren. Micobacterias. In: Microbiologia médica e imunologia. 12. ed. Porto Alegre: ARTMED, 2014. 184-86. p.

2. Einar Wilder-Smith. Diagnosis of pure neuritic leprosy. Neurol $J$ Southeast Asia 2002; 7: 61-63.

3. Natasja HJ Van Veen et al. Decompressive surgery for treating nerve damage in leprosy. Cochrane Database of Systematic Reviews 2009, Issue 1.

4. Marcelo Grossi Araújo. Hanseníase no Brasil. Revista da Sociedade Brasileira de Medicina Tropical. 36(3): 373-382, maijun, 2003.

5. World Health Organization. Weekly epidemiological Record. global leprosy situation, 2012. 2012, 87, 317-328.

6. "Leprosy" (http://www.who.int/mediacentre/factsheets/fs101/ en/). WHO. accessed on August 7, 2015.

7. Carney D. Matheson, Kim K. Vernon, Arlene Lahti, Renee Fratpietro, Mark Spigelman, Shimon Gibson, Charles L. Greenblatt, Helen D. Donoghue. Molecular Exploration of the First-Century Tomb of the Shroud in Akeldama, Jerusalem. PLoS ONE, 2009;

8. Maria Lucia Fernandes Penna ET al. Comportamento epidemiológico da hanseníase no Brasil. Saúde Brasil 2008: 20 anos de Sistema Único de Saúde (SUS) no Brasil. Disponível em: http:// portalsaude.saude.gov.br/portalsaude/arquivos/pdf/2013/ Fev/28/saudebrasil2009 parte2 cap12.pdf

9. Rabello FE, Fraga S. Atlas de Dermatologia. Rio de Janeiro: Guanabara Koogan; 1970. 304

10. Ridley D S \& Jopling W H. Classification of leprosy according to immunity: a five-group system. Int. J. Leprosy 34: 255-73, 1966.

11. Cacilda Silva Souza. Medicina, Ribeirão Preto. 30: 325-334, jul./ set. 1997.

12. Wim H. Van Brakel et al. International workshop on neuropathology in leprosy - consensus report. Lepr Rev (2007) 78, 416-433.

13. David M. Scollard. The biology of nerve injury in leprosy. Lepr Rev (2008) 79, 242-253.

14. Diana N. Lockwood, Paul R. Saunderson. Nerve damage in leprosy: a continuing challenge to scientists, clinicians and service providers. International Health 4 (2012) 77- 85

15. M Madhusudan. Leprous Neuritis: A Diagnostic Dilemma. Continuing Medical Education. 1999, volume 65,issue 2, page: 59-65.

16. Winnie W. Ooi, And Jayashri Srinivasan. Leprosy And The Peripheral Nervous System: Basic And Clinical Aspects. Muscle \& Nerve October 2004

17. Job, C. K. Pathology and pathogenesis of leprous neuritis: a preventable and treatable complication. International journal of leprosy. Volume 69. Number 2 (Suppl.)

18. Osvaldo J.M. Nascimento ET al. Leprosy late-onset neuropathy: an uncommon presentation of leprosy. Arq Neuropsiquiatr 2012; 70(6): 404-406
19. Jardim MR, Chimelli L, Faria SCR, et al. Clinical, electroneuromyographic and morphological studies of pure neural leprosy in a Brazilian referral center. Lepr Rev 2004; 75 : 242-253.

20. Medonça VA et AL. Imunologia da hanseníase. An Bras Dermatol. 2008; 83(4): 343-50.

21. Bryceson A, Pfaltzgraff RE. Complications due to nerve damage. In: Medicine in the tropics: leprosy. 3th ed. Edinburgh: Churchill Livingstone; 1990. p. 133-51.

22. Vyna Maria Cruz Leite. José Wellington de Oliveira Lima. Heitor de Sá Gonçalves. Neuropatia silenciosa em portadores de hanseníase na cidade de Fortaleza, Ceará, Brasil. Cad. Saúde Pública, Rio de Janeiro, 27(4): 659-665, abr, 2011

23. Bhat RM, Prakash C. Leprosy: An Overview of Pathophysiology. Interdisciplinary Perspectives on Infectious Diseases Volume 2012.

24. Donaghy M. Enlarged peripheral nerves. Practical Neurology, 2003, 3, 40-45

25. Kuhn, L. Historical Aspects of Leprosy. Clin Infect Dis. (2010) 51 (4): 476-477.

26. Kumar A. Nerve thickening in leprosy patients and risk of paralytic deformities: a field based study in Agra, India. Lepr Rev (2004) 75, 135-142

27. Husain S. Decompression of peripheral nerve trunks in leprosy prevents the development and progression of deformities? Indian J Lepr 2013, 85: 163-169.

28. Leprosy as a neurological disease. Lancet Neurol. 2009 Mar; 8(3): 217

29. Monteiro CBM, Almeida Junior AD, Wajnzstejn R. Project Management in Health and Medical Research. Journal of Human Growth and Development. 2014; 24(3): 239-242

30. $\mathrm{R}$ Development Core Team (2008). R: A language and environment for statistical computing. $R$ Foundation for Statistical Computing, Vienna, Austria. ISBN 3-900051-07-0, URL http://www.R-project.org.

31. Solomon $S$ et al. Incidence of Nerve Damage in Leprosy PatientsTreated with MDT. International Journal on Leprosy. Volume 66, Number 4. 1998.

32. Jardim, MR. et al. Pure neural leprosy: Steroids prevent neuropathy progression. Arq Neuropsiquiatr 2007; 65(4-A): 969-973.

33. Malaviya GN: Sensory perception in leprosy-neurophysiological correlates, Int J Lepr Other Mycobact Dis 71(2): 119-124, 2003.

34. Agrawal A, Pandit L, Dalal M, Shetty JP Neurological manifestations of Hansen's disease and their management. Clinical Neurology and Neurosurgery 107 (2005) 445-454. 
35. Wim H. van Brakel et al. Early Diagnosis of Neuropathy in Leprosy-Comparing Diagnostic Tests in a Large Prospective Study (the INFIR Cohort Study). PLoS Negl Trop Dis. 2008 Apr 2; 2(4): e212.

36. Jan $H$ Richardus et al. Incidence of acute nerve function impairment and reactions in leprosy: a prospective cohort analysis after 5 years of follow-up. International Journal of Epidemiology 2004; 33: 337-343.

37. Croft RP et al. Nerve function impairment in leprosy: design, methodology, and intake status of a prospective cohort study of 2664 new leprosy cases in Bangladesh (The Bangladesh Acute Nerve Damage Study). Lepr Rev. 1999 Jun; 70(2): 140-59.

38. Fernández-Domínguez A. P., Estrada R., and Galarraga J. Neuropathy of leprosy: characteristics of cases in 1962-1995. Revista de neurologia, 1999 Feb 1-15, Volume 28, Issue 3, p.232-6.

\section{Comment on this article:}

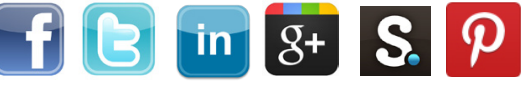

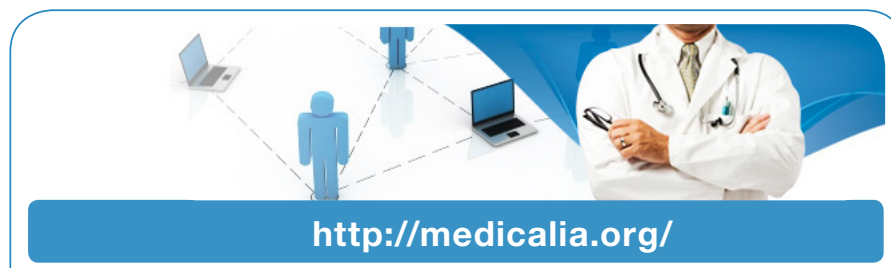

Where Doctors exchange clinical experiences, review their cases and share clinical knowledge. You can also access lots of medical publications for free. Join Now!

\section{Publish with iMedPub}

http://www.imed.pub

International Archives of Medicine is an open access journal publishing articles encompassing all aspects of medical science and clinical practice. IAM is considered a megajournal with independent sections on all areas of medicine. IAM is a really international journal with authors and board members from all around the world. The journal is widely indexed and classified Q1 in category Medicine. 